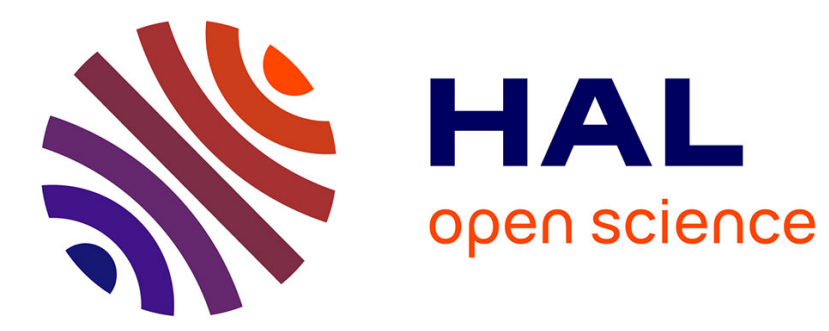

\title{
Self-reported attitudes about medication in Lebanese people with epilepsy
}

\author{
Lara Mroueh, Farid Boumédiène, Jérémy Jost, Voa Ratsimbazafy, \\ Pierre-Marie Preux, Pascale Salameh, Amal Al-Hajje
}

\section{To cite this version:}

Lara Mroueh, Farid Boumédiène, Jérémy Jost, Voa Ratsimbazafy, Pierre-Marie Preux, et al.. Selfreported attitudes about medication in Lebanese people with epilepsy. Epilepsy \& Behavior, 2019, 98, pp.80-87. 10.1016/j.yebeh.2019.06.028 . hal-02274107

\section{HAL Id: hal-02274107 \\ https://hal-unilim.archives-ouvertes.fr/hal-02274107}

Submitted on 25 Oct 2021

HAL is a multi-disciplinary open access archive for the deposit and dissemination of scientific research documents, whether they are published or not. The documents may come from teaching and research institutions in France or abroad, or from public or private research centers.
L'archive ouverte pluridisciplinaire HAL, est destinée au dépôt et à la diffusion de documents scientifiques de niveau recherche, publiés ou non, émanant des établissements d'enseignement et de recherche français ou étrangers, des laboratoires publics ou privés.

\section{다)(1) $(5$}

Distributed under a Creative Commons Attribution - NonCommerciall 4.0 International 


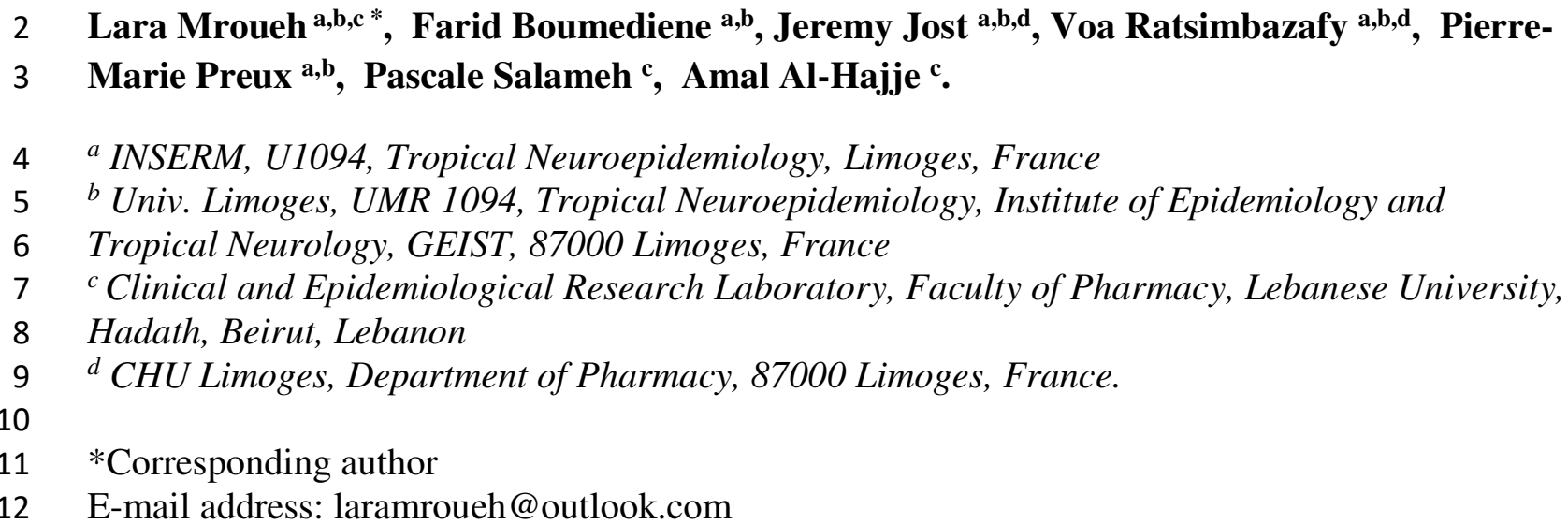

Number words/Abstract: 314

Number words/Article: 3627

Figure 1: Percentages of 4-MMAS answers and adherence score

Table 1: Description of the study population

Table 2: Description of health status and history of epilepsy

Table 3: Comparison of people with epilepsy with positive and negative attitudes towards medication

Table 4: Final results of regression using the status of attitudes as the dependent variable

Table 5: Final results of regression using the seizure control as the dependent variable (1) . 
Abstract

Background: Epilepsy is a common worldwide neurological disorder. For people with epilepsy, adherence and attitudes towards medication is a crucial step to improve efficacy of prescribed treatment and to prevent seizures.

Objectives: The first aim of this study was to evaluate attitudes towards antiepileptic medications in Lebanese population. Secondary aims were to assess factors affecting attitudes and associated with epilepsy control.

Material and Methods: A cross-sectional study was conducted in out-patients neurology clinics located in Beirut-Lebanon. Data was collected using a structured questionnaire. Self-report of medication taking behaviors were assessed using the abbreviated (4-items) Morisky Medication Adherence Scale (MMAS4). Epilepsy was considered as controlled if the patient had no seizures in the last 6 months.

Results: Among 250 people with epilepsy (PWE) recruited in this study, male-to-female ratio was 0.87 (116/134), and 50.8\% were married. Mean duration of epilepsy was $13.7 \pm 12.8$ years. Valproate was the most common antiepileptic drug used followed by levetiracetam and carbamazepine. About $60.8 \%$ of the population presented partial epilepsy. Uncontrolled epilepsy was present in more than half of participants (55.2\%), with only $32.4 \%$ had positive attitudes to their medication. Positive attitudes towards antiepileptic increased in people who found their treatment was efficacious (OR=4.9; 95\%CI 1.2-20.0; $\mathrm{p}=0.03)$, who had controlled epilepsy $(\mathrm{OR}=3.4 ; 95 \% \mathrm{CI} 1.6-7.1 ; \mathrm{p}=0.001)$, and who were diagnosed as people with epilepsy between the age of 12-20 years $(\mathrm{OR}=3.1 ; 95 \% \mathrm{CI} 1.1-8.4 ; \mathrm{p}=0.03)$. Oppositely, these attitudes decreased in participants who felt their treatment as an economic burden $(\mathrm{OR}=0.2 ; 95 \%$ CI 0.1 $0.4 ; \mathrm{p}<0.001)$, and in depressive people ( $\mathrm{OR}=0.4 ; 95 \%$ CI 0.2-0.9; $\mathrm{p}=0.04)$. Controlled epilepsy was higher in people who contacted a neurologist if seizure occurred, in people with positive attitudes, and after a long duration of disease, but it decreased if patient didn't follow neurologist's instructions in fasting period.

Conclusions: Lebanese PWE were less likely to have positive attitudes towards medication, which may lead to poor epilepsy control. Depression and economic burden were the major factors decreased these attitudes. Identifying factors affecting attitudes to medication and leading to controlled epilepsy may help clinicians to elaborate educational programs to optimize medication adherence.

Keywords: Epilepsy; Attitudes; Behaviors; Antiepileptic drug; Lebanon. 


\section{INTRODUCTION}

66 Epilepsy is a neurological chronic disorder that affects almost 70 million people of all ages 67 worldwide, of whom $85 \%$ live in developing countries [1]. According to the International League 68 Against Epilepsy (ILAE), epilepsy is a brain disease defined by at least two unprovoked (or 69 reflex) seizures occurring more than 24 hours apart [2]. Epilepsy treatment gap is defined as 70 frequency of people with active epilepsy who need treatment but don't receive it $[3,4]$, exceeded $7175 \%$ in most low-income countries and in rural regions $[5,6]$.

72 Antiepileptic drugs (AED) are essential to control epilepsy, and are able to reduce seizures 73 frequency in almost $67 \%$ of people with epilepsy (PWE) [7]. Despite a large number of AED 74 present to date, low adherence and negative attitudes lead to failure of treatment. Studies showed 75 that non-adherence to antiepileptic medication was associated with poor seizure control [8]. Many studies showed that worse attitudes and non-adherence proportions among PWE were

77 similar to other chronic diseases and ranged between $30 \%$ and 50\% [9-13]. Lack of adherence to 78 AED might lead to therapeutic failure, poor quality of life, and increase in the risk of seizures 79 recurrence $[8,14,15]$. Patients' non-adherent having negative attitudes towards drugs present 80 uncontrolled epilepsy, and are at higher risk of status epilepticus (prolonged seizures) [16]. As a

81 result, number of hospital admissions, healthcare costs, rate of morbidity and mortality increase 82 [17-22]. Furthermore, the risk of sudden unexpected death in epilepsy (SUDEP) is higher in non83 adherent PWE [23].

84 Based on these consequences, identifying the barriers to patient's attitudes towards AED is 85 considered essential for clinicians to develop strategies in order to improve attitudes to medication 86 in PWE [11]. Some known factors are unmodifiable by a neurologist in treatment strategy, such as 87 age of disease onset, epilepsy etiology (symptomatic, idiopathic, and cryptogenic), and location of 
88 epileptogenic zone (partial or generalized) [10]. The other modifiable factors are socio-economic

89 factors, health care factors, comorbidities, cultural beliefs about epilepsy, frequency of seizures,

90 treatment management, adverse events of AED, type/ frequency of medication use, cost of

91 treatment and forgetfulness [23,24]. These factors can be controlled, and health care providers

92 should resolve these problems to improve patient's attitudes to treatment.

93 A literature review showed that multiple factors that influence medication adherence worldwide.

94 But, very few published studies evaluated attitudes to medication among PWE in Arab countries.

95 Two countries (Saudi Arabia and Palestine) have evaluated adherence to AED [10,25]. More

96 studies are necessary to detect these factors among Arabic people who present some specific

97 habits, attitudes and cultures [10].

98 For this purpose, this study aims firstly to evaluate attitudes towards antiepileptic medications in 99 Lebanese population, and secondary to assess factors affecting attitudes and associated with 100 epilepsy control.

101

\section{2. MATERIAL AND METHODS}

\section{2.1. Study design}

104 A cross-sectional study was conducted in outpatient neurologic clinics of three tertiary care 105 hospitals, two medical centers and ten private neurologic clinics located in Beirut-Lebanon. Beirut 106 is the capital and largest city of Lebanon. Greater Beirut is generally considered as a growth of 107 Beirut city and its peripheral areas (suburbs). These areas are urbanized and considered densely 108 populated 
109 This survey was carried out over a period of 6 months from February $1^{\text {st }}, 2018$ to July $30^{\text {th }}, 2018$.

110 The clinics included in this study are visited by PWE from different Lebanese regions. The list of

111 neurologists was obtained from Lebanese Order of Physicians.

112 The estimated sample size was 217 patients (with a 95\% confidence interval (CI), and a 5\% 113 precision error [26]) based on a previous published study using Morisky scale and reporting that 114 only $17 \%$ of Lebanese patients with chronic diseases were adherent to their treatment [27].

115 Lebanese outpatients above 18 years of age, diagnosed with epilepsy by a neurologist, and taking 116 at least one AED for at least one month were included in the study.

117 Participants who had mental retardation or intellectual disability, who were newly diagnosed with 118 epilepsy (adherence of patient who didn't take AED for at least 4 weeks can't be evaluated), 119 presented non-epileptic psychogenic seizures, who were taking AED for neuropathic pain, and 120 pregnant women were not included. Also, participants who didn't give written consent to 121 participate in the study were not included.

122

\section{2.2. Data collection}

124 Data was collected using a structured questionnaire prepared at first in English, and then presented 125 in Arabic, the local language, to facilitate comprehension for patients.

126 It was translated into Arabic Language by two independent translators. A back translation to 127 English was done by another bilingual translator, who was not included in developing the initial 128 version. The original Arabic version and the back translated English version were compared to 129 resolve any inconsistency. A pilot study was done with 20 PWE to identify any problem in 130 comprehension. These participants were not included in the final sample of the study. 
131 The questionnaire was divided into six sections. Demographic data, natural history of

132 epilepsy/etiology, and treatment were parts used from standardized questionnaire for investigation

133 of epilepsy in tropical countries [28].

134 - Socio-demographic characteristics: age, gender, height and weight, region of residence,

135 education level, occupation, marital status, number of workers/family, presence of medical

136 insurance.

137 - History of epilepsy: duration of epilepsy, age of disease onset, family history, seizures in last 5

138 years, seizure control, seizure type, and etiology.

139 - Treatment: type of AED, number of AED, number of pills/day, frequency of administration,

140 reason for discontinuing treatment, appearance of side effects and its type (such as tiredness,

141 nervousness, headache, skin's problem, hair loss, weight gain/loss, blurred vision, upset stomach,

142 difficulty in concentrating, depression, disturbed sleep)[29], and measure serum level of AED.

143 - Health status: presence of comorbidities (any chronic disease other than epilepsy), and 144 medication history.

145 - Self-report of medication taking behaviors were assessed using the abbreviated (4-items)

146 Morisky Medication Adherence Scale (MMAS-4).

147 - General behaviors and attitudes towards medication: in absence/occurrence of seizures, in

148 fasting/busy periods, if side effects appear, if no money/health coverage, if any neighbor's patient

149 advices to stop medication, if participant forget to take medication, frequency of neurology visits,

150 follow healthcare provider instruction, efficacy of treatment approved by participant, and if a

151 treatment was an economic burden. These variables were not considered by MMAS-4.Data

152 collection was done by a bilingual, Arabic native investigator using a face to face interview with

153 PWE. All PWE attending neurology clinics and fulfilling inclusion criteria were included in this 
154

155

156

157

158

159

160

161

162

study. The interviewer checked the patient's file to confirm diagnosis and inclusion criteria before taking written informed consent. Data concerning history of epilepsy, medication and health status was extracted from patient's file. The questionnaire was completed for all patients by a unique investigator during a 15 minutes face to face interview, during the patient's visit to the neurologist's clinic. The same questions were asked in the same manner and tone in Arabic to all patients to facilitate direct understanding.

\subsection{Definition of dependent variables}

In this study, seizure control was defined as studies done in Brazil and UK [30,31]. Epilepsy was arbitrarily classified as controlled if the patient had no seizures in the last 6 months and uncontrolled if he/she had at least one seizure in the last 6 months.

The MMAS-4 is a standardized validated questionnaire, used in this study to evaluate and reflect general health behaviors toward AED therapy. This structured self-report consists of 4 items with four "yes/no" questions [32,33].

Based on previous studies [10,30,34], each item is coded 0 if the answer is "Yes" and 1 if "No". A score can range from 0 to 4 . Patients who had a score $=4$ were considered adherent having positive attitudes towards AED and who had a score $<4$ were considered non-adherent having negative attitudes. The adherent state was considered for a patient responding "No" to all 4 questions and this reflects positive attitudes. However, if one response was "Yes", a patient was considered non-adherent with negative attitudes. Cronbach's alpha was measured to evaluate reliability of the translated Arabic scale in this study. It was 0.705 , which indicates a high level of internal consistency for a scale in this sample. 


\section{2.4. Data analysis}

178 Statistical analysis was done with the Statistical Package for the Social Sciences (SPSS) software,

179 version 20. Descriptive analysis was used to describe qualitative (by frequency and percentage)

180 and quantitative (by mean and standard deviation) variables. Comparative analysis was carried

181 using Pearson's chi-square test or Fisher's exact test to report significant differences for 182 qualitative variables between PWE with positive and negative attitudes. Student's t-test was used

183 to compare the means between positive and negative attitudes groups. Variables having p-value $184<0.2$ were included in the multivariate model. Backward logistic regression was done to determine 185 predictors affecting attitudes to treatment and controlled epilepsy. The variable "Attitudes towards 186 AED" was dichotomized into a dependent variable as "Positive/ Negative", and seizure control 187 into "Controlled/ Uncontrolled". Statistical tests were considered significant with a p-value $<0.05$ 188 and a confidence interval of $95 \%$.

\section{RESULTS}

\section{3.1. Socio-demographic and clinical characteristics}

192 Two hundred fifty patients were recruited, with an average age of $40.2( \pm 14.8)$ ranging from 18 to 19385 years. More than half of PWE (53.6\%) were females and lived in Beirut (62.0\%). The majority 194 of the participants were unemployed (52.4\%). Around quarter of this population (24.8\%) have 195 never been to school (Table 1).

196 Of all the participants, $56.8 \%$ had comorbidities, where hypertension and heart problems (cardiac 197 insufficiency/ arrhythmia/ atrial fibrillation) were the most common (24.0\%) followed by 198 depression and anxiety (12.8\%). Seventy-six patients (30.4\%) had a family history of epilepsy. 199 The mean duration of epilepsy was 13.7 years $( \pm 12.8)$. More than half of PWE $(55.2 \%)$ had an 
200

201

202

203

204

205

206

207

208

209

210

211

212

213

214

215

216

217

218

219

220

221

uncontrolled epilepsy. The majority of population (61.6\%) presented partial epilepsy, with symptomatic etiology in $57.6 \%$ of cases. Monotherapy was prescribed in $60 \%$ of PWE; Valproic acid $(50.0 \%)$, levetiracetam $(26.4 \%)$, and carbamazepine $(23.6 \%)$ were the most common AED prescribed. More than half of participants $(58.0 \%)$ didn't take their medication daily, due to several reasons, including forgetfulness $(37.9 \%)$, medication cost (13.1\%), unavailability of drugs (13.1\%), or absence of seizures (13.1\%). Side effects of AED affected 57.2\% of PWE (Table 2).

\subsection{Attitudes towards antiepileptic drugs}

More than half of the patients $(56.0 \%)$ said they forgot to take their AED. Thereby, within the remaining some patients were classified non-adherent having negative attitudes because they had stopped taking medication if they felt better (30.4\%) or worse $(20.4 \%)$. However, only $32.4 \%$ of the study population were considered having positive attitudes to antiepileptic medication based on the sum of MMAS-4 score (Figure 1).

(1)

\subsection{Comparative analysis between PWE with positive and negative attitudes towards} medication

Regarding disease history, uncontrolled epilepsy was found in 44.4\% of PWE with positive attitudes to AED compared to $60.4 \%$ of PWE with negative attitudes $(\mathrm{p}=0.02)$. Forgetfulness was the main reason for stopping medication in $32.5 \%$ of PWE with negative attitudes compare to no

19 PWE having positive attitudes group. Experience of side effects was higher among PWE having 20 negative attitudes $(65.1 \%)$ than others $(40.7 \%)(\mathrm{p}<0.001)$. Measure of the serum level of AED was done by $76.8 \%$ of PWE having positive attitudes compare to. 31.3\% of PWE with negative 
222

223

224

225

226

227

attitudes $(\mathrm{p}<0.001)$. Depression was significantly higher $(\mathrm{p}=0.04)$ among PWE with negative attitudes $(27.8 \%)$ than in those who had positive attitudes $(16 \%)$.

As for the patient's behaviors, $17.2 \%$ of PWE with negative attitudes forgot to take medicine compare to $7.4 \%$ of PWE with positive attitudes in a busy period. A proportion of $38.5 \%$ of PWE having negative attitudes could not buy treatment compared to $23.5 \%$ of PWE having positive attitudes due to a lack of money or no health coverage. In fasting period, $44.4 \%$ of PWE with positive attitudes increased time between 2 doses $(>12 \mathrm{~h})$ compare to $26 \%$ of others Also, increasing dose when seizure occurs $(\mathrm{p}=0.02)$, stopping medication in seizure-free period or when side effects appear $(\mathrm{p}<0.001)$, and skipping doses in fasting period $(\mathrm{p}=0.003)$ were factors which significantly differed between 2 groups of PWE with positive and negative attitudes (Table 3).

\subsection{Factors affecting attitudes towards antiepileptic medications}

This study showed that seven factors predict patient's attitudes. Efficacy of treatment was an important predictor $(\mathrm{OR}=4.9 ; 95 \% \mathrm{CI} 1.2-20.0 ; \mathrm{p}=0.03)$. Controlled epilepsy also increased the odds of having positive attitudes $(\mathrm{OR}=3.4 ; 95 \% \mathrm{CI} 1.6-7.1 ; \mathrm{p}=0.001)$. Onset of epilepsy at age between 12-20 years was a factor leading to increased positive attitudes, compared to onset at age $<12$ years $(\mathrm{OR}=3.1 ; 95 \% \mathrm{CI} 1.1-8.4 ; \mathrm{p}=0.03)$.

While, patient's positive attitudes decreased in participants who thought that their treatment was an economic burden $(\mathrm{OR}=0.2 ; 95 \% \mathrm{CI}$ 0.1-0.4; $\mathrm{p}<0.001)$, depressive PWE $(\mathrm{OR}=0.4$; 95\%CI 0.2$0.9 ; \mathrm{p}=0.04)$, who visited their neurologist clinics every year $(\mathrm{OR}=0.2 ; 95 \% \mathrm{CI} 0.04-0.5 ; \mathrm{p}=0.002)$ or every few years (only when a seizure occurs) $(\mathrm{OR}=0.2 ; 95 \% \mathrm{CI} 0.1-0.7 ; \mathrm{p}=0.01)$, and in older people $(\mathrm{OR}=0.97 ; 95 \% \mathrm{CI} 0.94-0.99 ; \mathrm{p}=0.02)$ (Table 4). 


\section{3.5. Factors affecting controlled epilepsy}

246 In this study, controlled epilepsy was higher in people who contact a specialist if seizure occurs $247(\mathrm{OR}=2.9 ; 95 \%$ CI 1.3-6.5; $\mathrm{p}=0.01)$, in PWE who had positive attitudes towards AED (OR=1.9;

248

249

250

251

252

253

254

255

256

257

258

259

260

261

262

263

264

266

265 A study conducted in essential hypertension established the concurrent and predictive validity of 95\%CI 1.1-3.4; $\mathrm{p}=0.03)$, and after a long duration of disease (OR=1.04; 95\%CI 1.02-1.07; $\mathrm{p}<0.001)$. However, risk of controlled seizures decreased if patient didn't follow neurologist's instructions in fasting period $(\mathrm{OR}=0.5 ; 95 \% \mathrm{CI} 0.3-0.9 ; \mathrm{p}=0.03)$ (Table 5).

\section{DISCUSSION}

Only $32.4 \%$ of PWE presented positive attitudes to AED, similar to a study from Ethiopia [9], but lower than findings in other countries such as Palestine (36.0\%) [25], England (41.0\%) [35], Lao (57.6\%) [36], and Saudi Arabia (61.7\%) [10]. This variation between countries could be due to different habits, behaviors, cultures between populations [10].

Four indirect methods are used to measure medication adherence in the outpatient setting [37]:

Self report, electronic medication monitoring, pharmacy refill rates and pill counts.

Electronic medication-measurement systems are expensive and rarely available in the outpatient setting. Pharmacy refill rates is not applicable because drugs (AED included) in Lebanon are delivered without prescription and do not require a renewal of prescription at every purchase. Also, it was difficult to count number of pills and to compare with the total number of pills received by a patient because the patient was seen only once, and did not carry his pills during his neurologist's visit. So we chose MMAS-4, a simple and economical self-reporting method. MMAS-4 regarding blood pressure measurements recorded throughout a 3-year follow-up period 
267 [32]. This self-reporting method is used for different chronic diseases, epilepsy included, in 268 several countries and populations $[9,10,25,30,35,36]$.

269 However, a comparison with studies using other methods to evaluate adherence shows that a low 270 percentage of adherence was more present in studies using subjective methods such as MMAS. In 271 studies using MMAS to estimate adherence in PWE, percentage of adherence ranged between $27220 \%$ and $55 \%[30,35,36,38]$. However, objective measures such as a medication possession ratio, 273 which definition and estimation differ between studies, show that adherence varied between 50\% 274 and $65 \%[12,17,19,39,40]$. In addition, a therapeutic drug concentration monitoring in prospective 275 studies show that adherence to medication was around $60 \%[41,42]$.

277 This study identified three key factors that increase positive attitudes in PWE. These attitudes 278 were present in people who had good perception toward AED, and who were correctly motivated 279 [43]. The PWE who were satisfied and felt that treatment was effective had more positive attitudes 280 in this population.

281 Controlled epilepsy is a factor leading to increased positive attitudes in this study. When epilepsy 282 is controlled, adherence and positive health behaviors to AED increased. This is in agreement with 283 other studies [15,30].

284 Attitudes to medication were also associated with age of epilepsy onset. People diagnosed as 285 epileptic at adolescence (12-20 years) had more positive attitudes than those diagnosed during 286 childhood ( $<12$ years). Adolescents were more able to follow instructions of neurologists, and 287 learn more about their disease and treatment. In pediatric patients, parents have a critical role to 288 improve adherence. However, they may tend to be fearful and stressed, this may negatively affect 289 attitudes to AED [44]. 
290 Oppositely, positive attitudes to medication decreased by four factors. Positive attitudes were

291 lower in PWE who felt that their treatment was an economic burden, similar to another study

292 conducted in Ethiopia [45]. Cost of medications was found to be a big burden due to absence of

293 health coverage for some Lebanese people

294 Depressive PWE were less adherent with negative attitudes to AED. Another study showed also a 295 significant correlation between medication adherence and depressive status [46].

296 PWE who visit neurologist clinic only every year or every few years had less positive attitudes.

297 Patient education about the disease and treatment is essential to resolve patient distress and 298 improve patient's attitudes to medication $[15,47]$.

299 Positive attitudes towards antiepileptic medications decreased in older age. In Ethiopia, older

300 PWE were less adherent with negative attitudes [9], in agreement with another study done in 301 China that reported the same association [8]. Older people present physical difficulties and cognitive problems making it difficult to follow healthcare provider's instructions [48]. However, presence of other comorbidities, complexity of treatment regimen, and multiple daily dosing decreased also adherence [44].

The reasons for discontinuation of treatment in this study included forgetfulness, high medication cost, adverse effects, unavailability of drugs, inefficacity of treatment and absence of seizures.

Forgetfulness was the main reason for non-adherence and discontinuing treatment in this study. This was reported also in other studies $[8,9,49,50]$, which found that forgetfulness was the key reason for being non-adherent. Most people may forget to take medication when they are busy at work, away from their home or while travelling. High cost of drugs was significantly associated with decreased adherence, similar to a study done in China [8]. PWE who experienced adverse effects of AED had negative attitudes. A common cause for stopping antiepileptic treatment, and 
313 limiting adherence without consulting neurologist was adverse effects [8,51]. PWE who stop

314 taking their medication when the drug is not available had negative attitudes than those who

315 didn't. Thus, the inability to obtain treatment in this population leads to decreased adherence and

316 positive attitudes to medication. The Lebanese government should provide and preserve the

317 required drugs in the public sector at any time in a better manner. Participants who had negative

318 beliefs about their treatment were significantly non-adherent to AED. This negative perception

319 was probably due to treatment failure and recurrence of seizures. These results were similar to

320 another study conducted in UK [12].

321

322 Controlled epilepsy was positively associated with adherence and positive attitudes to AED. A

323 reciprocal significant association was found between patient's attitudes and controlled epilepsy,

324 where low medication adherence and negative attitudes showed to be also a cause for uncontrolled

325 epilepsy, similar to results in other studies [14,52,53]. Precisely, PWE who stop treatment are

326 more likely to have uncontrolled epilepsy. This suggests that evaluation of adherence can predict

327 epilepsy outcome.

328 Duration of epilepsy was a factor affecting controlled epilepsy. PWE who were diagnosed as 329 epileptics since long time were more likely to have controlled epilepsy. Seizures may take longer 330 time to become controlled. Long duration leads to adaptation for this disease, and then improved 331 adherence. In Nigeria, PWE were more likely to have controlled epilepsy when they are in older 332 age [54].

333 However, controlled epilepsy decreased if patient didn't follow neurologist's instructions in 334 fasting period. Some research was carried out on PWE during the fasting month. During this 335 period, only two meals are consumed per day, separated by a fasting time of 11 to 18 hours 
depending on season [55]. A study done in Turkey showed that some of PWE had more seizures

337 during fasting month. This increase was probably due to changes in the way epilepsy medicine

338

339

340

342 This study was the first to evaluate attitudes to antiepileptic medications in Lebanese PWE, and 343 one among few studies done in the Arab world which has its specific culture and behaviors. 344 However, due to a lack of studies in Arab countries, we didn't have enough data to compare our 345 findings.

346 With a cross-sectional design, it is impossible to establish causal relationship. Some recall bias 347 may be present due to the fact that self-report was the method used to evaluate behaviors towards 348 medication. Self-report is the most practical method in the outpatient setting, but it tends to 349 overestimate responses compared to the objective methods. In addition to this, the overestimation 350 of acceptable responses may be due to the fact that the questionnaire was completed by the 351 investigator and not privately by the patient. This study evaluated medication problems related to 352 treatment acceptance and patient's attitudes towards medications; all people accepted to take AED 353 but a low level of positive attitudes was found.

354 Participants were recruited from neurology clinics due to necessity of accurate diagnosis, but 355 selection bias may be present. However, to reduce selection bias, and to be more representative, 356 PWE were recruited from different health structures (private clinics, clinics in hospitals, and 357 clinics in medical centers). Those health structures allow people from all economic stages to 358 access neurologists' consultation. Since PWE were recruited from neurologists' clinics, a high 
359 level of adherence was expected; however, low adherence was found. This approves diversity of 360 PWE recruited and reduces the risk of recruitment bias.

361 A longitudinal prospective study will be necessary to focused on people who discontinue their

362 medication after a long-time treatment. Persistence of adherence during a follow-up period could 363 be evaluated in future studies.

\section{CONCLUSIONS}

Lebanese PWE were less likely to have positive attitudes towards antiepileptic medications, which may lead to poor epilepsy control. The positive attitudes of PWE are cornerstone to improve epilepsy treatment, prevent recurrence of seizures, reduce the risk of hospitalization and improve quality of life. Diagnoses followed by pharmacological treatment are not enough in epilepsy management. Thus, evaluation of patient's attitudes is essential in clinical practice, and should be a base in treatment management to predict epilepsy control. Depression, economic burden and visiting neurologist's clinic every year or every few years predicted negative attitudes towards antiepileptic medications in our study. Non-respect of recommendations to neurologist leads in turn to uncontrolled epilepsy. Depressive people should be managed effectively by a specialist. Prescribing generic drugs with affordable costs and having access to a better social security systems in Lebanon are needed to provide medication to patients with no health insurance and thereby limit the economic burden felt by PWE. Contact neurologist and follow his recommendations in case of seizure occurrence or during fasting periods were necessary to control epilepsy.

380 Educating PWE and their families about disease and treatment management, adapting simple

381 medication regimens by neurologists (such as monotherapies to reduce number of pills, and 
382

383

384

385

386

387

388

389

390

391

392

393

394

395

396

397

398

399

400

401

402

403

404

405

406

407

408

409

410

extended-release drugs to reduce frequency of dosing), ensuring a good relationship between PWE and healthcare professionals, and attending regularly to appointments, are important for attaining good adherence to treatment. In fact, using easy reminders to take medications (pill reminder boxes, calendars, alarms, watches with beeper alarms, caregivers reminder) is important to optimize medication adherence and enhance positive attitudes for PWE. Educational programs about the disease and treatment are also necessary for attaining good attitudes towards medications for PWE.

\section{CONFLICT OF INTEREST}

There is no conflict of interest.

\section{FUNDING}

This research did not receive any specific grant from funding agencies in the public, commercial, or not-for-profit sectors.

\section{REFERENCES}

[1] Ngugi AK, Bottomley C, Kleinschmidt I, Sander JW, Newton CR. Estimation of the burden of active and life-time epilepsy: a meta-analytic approach. Epilepsia 2010;51:883-90. doi:10.1111/j.1528-1167.2009.02481.x.

[2] Fisher RS, Acevedo C, Arzimanoglou A, Bogacz A, Cross JH, Elger CE, et al. ILAE official report: a practical clinical definition of epilepsy. Epilepsia 2014;55:475-82. doi:10.1111/epi.12550.

[3] Kale R. Global Campaign against Epilepsy: the treatment gap. Epilepsia 2002;43:31-3.

[4] Meinardi H, Scott RA, Reis R, Sander JW, ILAE Commission on the Developing World. The treatment gap in epilepsy: the current situation and ways forward. Epilepsia 2001;42:136-49.

[5] Meyer A-C, Dua T, Ma J, Saxena S, Birbeck G. Global disparities in the epilepsy treatment gap: a systematic review. Bull World Health Organ 2010;88:260-6. doi:10.2471/BLT.09.064147. 
[6] Mbuba CK, Ngugi AK, Newton CR, Carter JA. The epilepsy treatment gap in developing countries: a systematic review of the magnitude, causes, and intervention strategies. Epilepsia 2008;49:1491-503. doi:10.1111/j.1528-1167.2008.01693.x.

[7] Elger CE, Schmidt D. Modern management of epilepsy: a practical approach. Epilepsy Behav 2008;12:501-39. doi:10.1016/j.yebeh.2008.01.003.

[8] Liu J, Liu Z, Ding H, Yang X. Adherence to treatment and influencing factors in a sample of Chinese epilepsy patients. Epileptic Disord 2013;15:289-94. doi:10.1684/epd.2013.0588.

[9] Hasiso TY, Desse TA. Adherence to Treatment and Factors Affecting Adherence of Epileptic Patients at Yirgalem General Hospital, Southern Ethiopia: A Prospective CrossSectional Study. PloS One 2016;11:e0163040. doi:10.1371/journal.pone.0163040.

[10] Gabr WM, Shams MEE. Adherence to medication among outpatient adolescents with epilepsy. Saudi Pharm J 2015;23:33-40. doi:10.1016/j.jsps.2014.05.003.

[11] Davis KL, Candrilli SD, Edin HM. Prevalence and cost of nonadherence with antiepileptic drugs in an adult managed care population. Epilepsia 2008;49:446-54.

[12] Chapman SCE, Horne R, Chater A, Hukins D, Smithson WH. Patients' perspectives on antiepileptic medication: relationships between beliefs about medicines and adherence among patients with epilepsy in UK primary care. Epilepsy Behav 2014;31:312-20. doi:10.1016/j.yebeh.2013.10.016.

[13] Getnet A, Woldeyohannes SM, Bekana L, Mekonen T, Fekadu W, Menberu M, et al. Antiepileptic Drug Nonadherence and Its Predictors among People with Epilepsy. Behav Neurol 2016;2016:3189108. doi:10.1155/2016/3189108.

[14] Kaddumukasa M, Kaddumukasa M, Matovu S, Katabira E. The frequency and precipitating factors for breakthrough seizures among patients with epilepsy in Uganda. BMC Neurol 2013;13:182. doi:10.1186/1471-2377-13-182.

[15] Hovinga CA, Asato MR, Manjunath R, Wheless JW, Phelps SJ, Sheth RD, et al. Association of non-adherence to antiepileptic drugs and seizures, quality of life, and productivity: survey of patients with epilepsy and physicians. Epilepsy Behav 2008;13:316-22. doi:10.1016/j.yebeh.2008.03.009.

[16] Skinner HJ, Dubon-Murcia SA, Thompson AR, Medina MT, Edwards JC, Nicholas JS, et al. Adult convulsive status epilepticus in the developing country of Honduras. Seizure 2010;19:363-7. doi:10.1016/j.seizure.2010.05.007.

[17] Ettinger AB, Manjunath R, Candrilli SD, Davis KL. Prevalence and cost of nonadherence to antiepileptic drugs in elderly patients with epilepsy. Epilepsy Behav 2009;14:324-9. doi:10.1016/j.yebeh.2008.10.021.

[18] Neligan A, Bell GS, Johnson AL, Goodridge DM, Shorvon SD, Sander JW. The long-term risk of premature mortality in people with epilepsy. Brain J Neurol 2011;134:388-95. doi:10.1093/brain/awq378.

[19] Faught E, Duh MS, Weiner JR, Guérin A, Cunnington MC. Nonadherence to antiepileptic drugs and increased mortality: findings from the RANSOM Study. Neurology 2008;71:1572-8. doi:10.1212/01.wnl.0000319693.10338.b9.

[20] Cramer JA, Wang ZJ, Chang E, Powers A, Copher R, Cherepanov D, et al. Healthcare utilization and costs in adults with stable and uncontrolled epilepsy. Epilepsy Behav 2014;31:356-62. doi:10.1016/j.yebeh.2013.09.046.

[21] Molugulu N, Gubbiyappa KS, Vasudeva Murthy CR, Lumae L, Mruthyunjaya AT. Evaluation of self-reported medication adherence and its associated factors among epilepsy 
patients in Hospital Kuala Lumpur. J Basic Clin Pharm 2016;7:105-9. doi:10.4103/09760105.189430.

[22] Goodman MJ, Durkin M, Forlenza J, Ye X, Brixner DI. Assessing adherence-based quality measures in epilepsy. Int J Qual Health Care 2012;24:293-300. doi:10.1093/intqhc/mzs017.

[23] O' Rourke G, O' Brien JJ. Identifying the barriers to antiepileptic drug adherence among adults with epilepsy. Seizure 2017;45:160-8. doi:10.1016/j.seizure.2016.12.006.

[24] Rikir E, Grisar T, Sadzot B. Treatment compliance in epileptic patients.A frequent and complex problem. Rev Med Liege 2010;65.

[25] Sweileh WM, Ihbesheh MS, Jarar IS, Taha ASA, Sawalha AF, Zyoud SH, et al. Selfreported medication adherence and treatment satisfaction in patients with epilepsy. Epilepsy Behav 2011;21:301-5. doi:10.1016/j.yebeh.2011.04.011.

[26] Charan J, Biswas T. How to calculate sample size for different study designs in medical research? Indian J Psychol Med 2013;35:121-6. doi:10.4103/0253-7176.116232.

[27] Al-Hajje A, Awada S, Rachidi S, Zein S, Bawab W, El-Hajj Z, et al. Factors affecting medication adherence in Lebanese patients with chronic diseases. Pharm Pract 2015;13:590. doi:10.18549/PharmPract.2015.03.590.

[28] Preux PM. Questionnaire in a study of epilepsy in tropical countries. Bull Soc Pathol Exot 1990 2000;93:276-8.

[29] Kuzmanova R, Stefanova I, Velcheva I, Stambolieva K. Translation, cross-cultural adaptation, and validation of the Bulgarian version of the Liverpool Adverse Event Profile. Epilepsy Behav 2014;39:88-91. doi:10.1016/j.yebeh.2014.08.124.

[30] Ferrari CMM, de Sousa RMC, Castro LHM. Factors associated with treatment nonadherence in patients with epilepsy in Brazil. Seizure 2013;22:384-9. doi:10.1016/j.seizure.2013.02.006.

[31] Smithson WH, Hukins D, Buelow JM, Allgar V, Dickson J. Adherence to medicines and self-management of epilepsy: a community-based study. Epilepsy Behav 2013;26:109-13. doi:10.1016/j.yebeh.2012.10.021.

[32] Morisky DE, Green LW, Levine DM. Concurrent and predictive validity of a self-reported measure of medication adherence. Med Care 1986;24:67-74.

[33] Morisky DE, Ang A, Krousel-Wood M, Ward HJ. Predictive validity of a medication adherence measure in an outpatient setting. J Clin Hypertens Greenwich Conn 2008;10:348-54.

[34] Moura LMVR, Carneiro TS, Cole AJ, Hsu J, Vickrey BG, Hoch DB. Association between addressing antiseizure drug side effects and patient-reported medication adherence in epilepsy. Patient Prefer Adherence 2016;10:2197-207. doi:10.2147/PPA.S119973.

[35] Jones RM, Butler JA, Thomas VA, Peveler RC, Prevett M. Adherence to treatment in patients with epilepsy: associations with seizure control and illness beliefs. Seizure 2006;15:504-8. doi:10.1016/j.seizure.2006.06.003.

[36] Harimanana A, Clavel S, Chivorakul P, Perez F, Preux P-M, Barennes H. Associated factors with adherence to antiepileptic drug in the capital city of Lao PDR. Epilepsy Res 2013;104:158-66. doi:10.1016/j.eplepsyres.2012.10.008.

[37] Hawkshead J, A. Krousel-Wood M. Techniques for Measuring Medication Adherence in Hypertensive Patients in Outpatient Settings. Dis Manag Health Outcomes 2007;15:10918. doi:10.2165/00115677-200715020-00006.

[38] Ahmad N, Othaman NI, Islahudin FH. Medication adherence and quality of life in epilepsy patients. Int J Pharm Pharm Sci 2013;5:401-4. 
[39] Briesacher BA, Andrade SE, Fouayzi H, Chan KA. Comparison of drug adherence rates among patients with seven different medical conditions. Pharmacotherapy 2008;28:437-43. doi:10.1592/phco.28.4.437.

[40] Manjunath R, Davis KL, Candrilli SD, Ettinger AB. Association of antiepileptic drug nonadherence with risk of seizures in adults with epilepsy. Epilepsy Behav EB 2009;14:372-8. doi:10.1016/j.yebeh.2008.12.006.

[41] Carpentier N, Jonas J, Frismand S, Vignal J-P, Rikir E, Baumann C, et al. Direct evidence of nonadherence to antiepileptic medication in refractory focal epilepsy. Epilepsia 2013;54:e20-23. doi:10.1111/j.1528-1167.2012.03695.x.

[42] Samsonsen C, Reimers A, Bråthen G, Helde G, Brodtkorb E. Nonadherence to treatment causing acute hospitalizations in people with epilepsy: an observational, prospective study. Epilepsia 2014;55:e125-128. doi:10.1111/epi.12801.

[43] Kyngäs H. Compliance with health regimens of adolescents with epilepsy. Seizure 2000;9:598-604. doi:10.1053/seiz.2000.0470.

[44] Loiselle K, Rausch JR, Modi AC. Behavioral predictors of medication adherence trajectories among youth with newly diagnosed epilepsy. Epilepsy Behav 2015;50:103-7. doi:10.1016/j.yebeh.2015.06.040.

[45] Getachew H, Dekema N, Awol S, Abdi A, Mohammed M. Medication adherence in epilepsy and potential risk factors associated with non adherence in tertiary care teaching hospital in southwest Ethiopia. Gaziantep Med J 2014;20:59. doi:10.5455/GMJ-30-45904.

[46] Shallcross AJ, Becker DA, Singh A, Friedman D, Jurd R, French JA, et al. Psychosocial factors associated with medication adherence in ethnically and socioeconomically diverse patients with epilepsy. Epilepsy Behav 2015;46:242-5. doi:10.1016/j.yebeh.2015.01.034.

[47] Lawson VL, Lyne PA, Harvey JN, Bundy CE. Understanding why people with type 1 diabetes do not attend for specialist advice: a qualitative analysis of the views of people with insulin-dependent diabetes who do not attend diabetes clinic. J Health Psychol 2005;10:409-23. doi:10.1177/1359105305051426.

[48] Cooper C, Carpenter I, Katona C, Schroll M, Wagner C, Fialova D, et al. The AdHOC Study of older adults' adherence to medication in 11 countries. Am J Geriatr Psychiatry 2005;13:1067-76. doi:10.1176/appi.ajgp.13.12.1067.

[49] Johnbull OS, Farounbi B, Adeleye AO, Ogunrin O, Uche AP. Evaluation of Factors Influencing Medication Adherence in Patients with Epilepsy in Rural Communities of Kaduna State, Nigeria. Neurosci Med 2011;02:299-305. doi:10.4236/nm.2011.24039.

[50] Paschal AM, Rush SE, Sadler T. Factors associated with medication adherence in patients with epilepsy and recommendations for improvement. Epilepsy Behav 2014;31:346-50. doi:10.1016/j.yebeh.2013.10.002.

[51] Tan X, Pharm B, Makmor-Bakry M, Pharm M, Lau C, Tajarudin F, et al. Factors affecting adherence to antiepileptic drugs therapy in Malaysia. Neurol Asia 2015:7.

[52] Birru EM, Shafi M, Geta M. Drug therapy of epileptic seizures among adult epileptic outpatients of University of Gondar Referral and Teaching Hospital, Gondar, North West Ethiopia. Neuropsychiatr Dis Treat 2016;12:3213-9. doi:10.2147/NDT.S119030.

[53] Nakhutina L, Gonzalez JS, Margolis SA, Spada A, Grant A. Adherence to antiepileptic drugs and beliefs about medication among predominantly ethnic minority patients with epilepsy. Epilepsy Behav 2011;22:584-6. doi:10.1016/j.yebeh.2011.08.007. 
547

548

549

550

551

552
[54] Obiako OR, Sheikh TL, Kehinde JA, Iwuozo EU, Ekele N, Elonu CC, et al. Factors affecting epilepsy treatment outcomes in Nigeria. Acta Neurol Scand 2014;130:360-7. doi:10.1111/ane.12275.

[55] Gomceli YB, Kutlu G, Cavdar L, Inan LE. Does the seizure frequency increase in Ramadan? Seizure 2008;17:671-6. doi:10.1016/j.seizure.2008.03.008. 


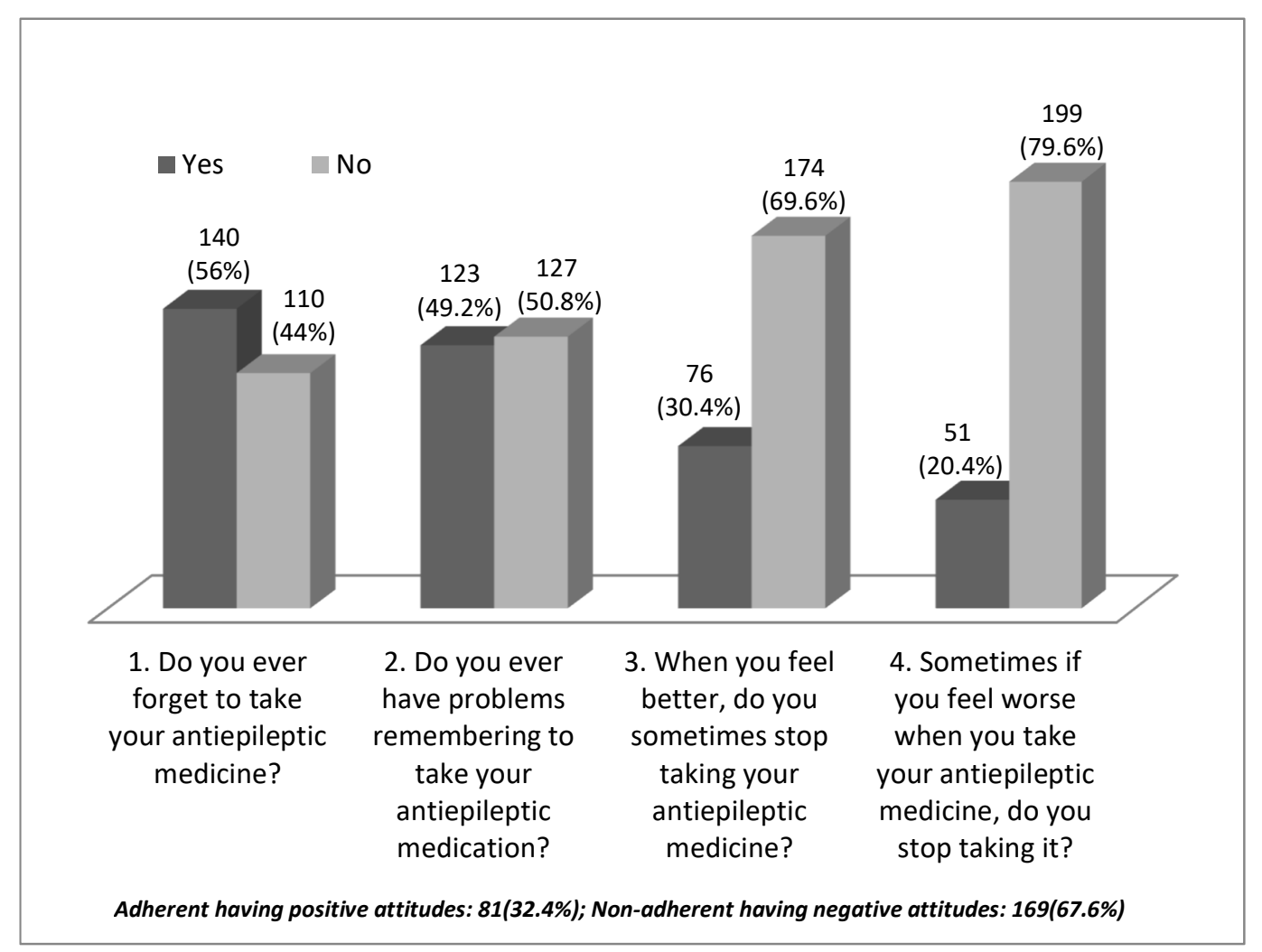

Fig.1. Percentages of 4-MMAS answers and adherence score 
Table 1. Description of the study population

\begin{tabular}{|c|c|c|}
\hline \multicolumn{2}{|c|}{ Variables } & \multirow[t]{2}{*}{$\begin{array}{c}n(\%) / \\
\text { Mean } \pm \text { SD }^{1} \\
\end{array}$} \\
\hline Sex & & \\
\hline & Females & $134(53.6)$ \\
\hline \multicolumn{3}{|l|}{ Region of residence } \\
\hline & Beirut & $155(62.0)$ \\
\hline & South & $30(12.0)$ \\
\hline & Mount Lebanon & $21(8.4)$ \\
\hline & Bekaa & $33(13.2)$ \\
\hline & North & $7(2.8)$ \\
\hline & Outside Lebanon & $4(1.6)$ \\
\hline \multicolumn{3}{|l|}{ Body mass index (BMI) ${ }^{2}$} \\
\hline & Underweight $\left(\mathrm{BMl}<18.5 \mathrm{~kg} / \mathrm{m}^{2}\right)$ & $7(2.8)$ \\
\hline & Normal weight $\left(\mathrm{BMl} \geq 18.5 \mathrm{~kg} / \mathrm{m}^{2}\right)$ & $105(42.0)$ \\
\hline & Overweight $\left(\mathrm{BMI} \geq 25 \mathrm{~kg} / \mathrm{m}^{2}\right)$ & $103(41.2)$ \\
\hline & Obese $\left(\mathrm{BMI} \geq 30 \mathrm{~kg} / \mathrm{m}^{2}\right)$ & $35(14.0)$ \\
\hline \multicolumn{3}{|l|}{ Education level } \\
\hline & Illiterate & $62(24.8)$ \\
\hline & Elementary & $60(24.0)$ \\
\hline & Intermediate & 41 (16.4) \\
\hline & Secondary & $32(12.8)$ \\
\hline & University & 55 (22.0) \\
\hline \multicolumn{3}{|l|}{ Occupation } \\
\hline & Unemployed & $131(52.4)$ \\
\hline & Employed/Self-employed & $97(38.8)$ \\
\hline & Shepherd/ Farmer & $3(1.2)$ \\
\hline \multirow{2}{*}{\multicolumn{3}{|c|}{ Marital status }} \\
\hline & & \\
\hline & Single lives alone & $11(4.4)$ \\
\hline & Single lives with family & $75(30.0)$ \\
\hline & Married & $127(50.8)$ \\
\hline & Divorced & $22(8.8)$ \\
\hline & Widowed & $15(6.0)$ \\
\hline Medical Insurance & & $138(55.2)$ \\
\hline & & $40.2 \pm 14.8$ \\
\hline BMI & & $25.8 \pm 6.0$ \\
\hline Number of workers/ family & & $1.4 \pm 1.1$ \\
\hline
\end{tabular}


Table 2. Description of health status and history of epilepsy

\begin{tabular}{|c|c|}
\hline Variables & Mean \pm SD $^{1} / \mathrm{n}(\%)$ \\
\hline Duration of epilepsy & $13.7 \pm 12.8$ \\
\hline Age of epilepsy onset & $26.5 \pm 18.8$ \\
\hline Family history of epilepsy & $76(30.4)$ \\
\hline Presence of seizures in last 5 years & $195(78.0)$ \\
\hline \multicolumn{2}{|l|}{ Seizure control } \\
\hline Uncontrolled (at least one seizure in last 6 months) & $138(55.2)$ \\
\hline Controlled (no seizure in last 6 months) & $112(44.8)$ \\
\hline \multicolumn{2}{|l|}{ Type of Comorbidities } \\
\hline Hypertension / Cardiac problems (cardiac insufficiency/ arrhythmia/ atrial fibrillation) & $60(24.0)$ \\
\hline Dyslipidemia & $29(11.6)$ \\
\hline Respiratory diseases (Asthma or COPD ${ }^{2}$ ) & $9(3.6)$ \\
\hline Angina & $7(2.8)$ \\
\hline Kidney disease & $4(1.6)$ \\
\hline Gastrointestinal disease & $24(9.6)$ \\
\hline Diabetes & $21(8.4)$ \\
\hline Thyroid disease & $19(7.6)$ \\
\hline Cerebrovascular Accident & $11(4.4)$ \\
\hline Depression/ Anxiety & $60(24.0)$ \\
\hline Psychosis/ Schizophrenia & $32(12.8)$ \\
\hline Migraine & $13(5.2)$ \\
\hline Cerebral Tumor & $7(2.8)$ \\
\hline Other Comorbidities (Parkinson, osteoporosis, rhumatological disease...) & $9(3.6)$ \\
\hline \multicolumn{2}{|l|}{ Seizure type } \\
\hline Simple partial & $50(20.0)$ \\
\hline Complex partial & $73(29.2)$ \\
\hline Secondary generalized & $31(12.4)$ \\
\hline Generalized tonic clonic & $80(32.0)$ \\
\hline Generalized myoclonic & $11(4.4)$ \\
\hline Generalized atonic & $3(1.2)$ \\
\hline Absence & $28(11.2)$ \\
\hline Others & $1(0.4)$ \\
\hline \multicolumn{2}{|l|}{ Epilepsy etiology } \\
\hline Idiopathic & $20(8.0)$ \\
\hline Cryptogenic & $86(34.4)$ \\
\hline \multirow{2}{*}{\multicolumn{2}{|c|}{ Type of $A E^{3}$ medication }} \\
\hline & \\
\hline Benzodiazepines & $36(14.4)$ \\
\hline Phenytoin & $19(7.6)$ \\
\hline Phenobarbital & $11(4.4)$ \\
\hline Carbamazepine & $59(23.6)$ \\
\hline Valproate & $125(50.0)$ \\
\hline Lamotrigine & $27(10.8)$ \\
\hline Levetiracetam & 66 (26.4) \\
\hline Oxcarbazepine & $12(4.8)$ \\
\hline Topiramate & $22(8.8)$ \\
\hline Lacosamide & $12(4.8)$ \\
\hline Perampanel & $1(0.4)$ \\
\hline \multicolumn{2}{|l|}{ AE therapy } \\
\hline Monotherapy & $150(60.0)$ \\
\hline $\begin{array}{r}\text { Bitherapy } \\
\end{array}$ & 67 (26.8) \\
\hline$>2$ antiepileptic medications & $33(13.2)$ \\
\hline Taking AED daily & $105(42.0)$ \\
\hline \multicolumn{2}{|l|}{$\begin{array}{l}\text { Taking AED daily } \\
\text { Main reason for stopping medication }\end{array}$} \\
\hline Forgetfulness & $55(37.9)$ \\
\hline High cost & 19 (13.1) \\
\hline Complexity of treatment regimen & $11(7.6)$ \\
\hline Experience of side effects & $12(8.3)$ \\
\hline Unavailability of drugs & $19(13.1)$ \\
\hline Perception of inefficacy & $10(6.9)$ \\
\hline Absence of seizures & $19(13.1)$ \\
\hline Experiencing of side effects & $143(57.2)$ \\
\hline
\end{tabular}


Table 3. Comparison of people with epilepsy with positive and negative attitudes towards medication

\begin{tabular}{|c|c|c|c|}
\hline Variables & $\begin{array}{c}\mathrm{n}(\%) \\
\text { Negative attitudes }\end{array}$ & $\begin{array}{c}\mathrm{n}(\%) \\
\text { Positive attitudes }\end{array}$ & $\mathrm{p}$-value \\
\hline \multicolumn{4}{|l|}{ Seizure control } \\
\hline Controlled & $67(39.6)$ & $45(55.6)$ & \\
\hline Uncontrolled & $102(60.4)$ & $36(44.4)$ & 0.02 \\
\hline \multicolumn{4}{|l|}{ Age onset disease } \\
\hline$<12$ years & $44(26.0)$ & $16(19.8)$ & \\
\hline $12-20$ years & $31(18.3)$ & $27(33.3)$ & \\
\hline 20-40 years & $54(32.0)$ & $15(18.5)$ & \\
\hline$>40$ years & $40(23.7)$ & $23(28.4)$ & 0.02 \\
\hline \multicolumn{4}{|l|}{ Measure serum level of AED if specialist prescribe this } \\
\hline 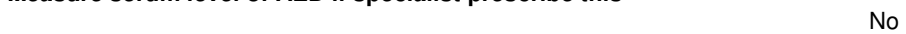 & $90(68.7)$ & $13(23.2)$ & \\
\hline Yes & $41(31.3)$ & $43(76.8)$ & $<0.001$ \\
\hline \multicolumn{4}{|l|}{ When a seizure occurs } \\
\hline Double a dose & $40(23.7)$ & $8(9.9)$ & \\
\hline Continue treatment normally & 64 (37.9) & 31 (38.3) & \\
\hline Contact a specialist & $65(38.5)$ & $42(51.9)$ & 0.02 \\
\hline \multicolumn{4}{|l|}{ In stable status (absence of seizures) } \\
\hline Stop medication & $49(29.0)$ & 0 & \\
\hline Reduce a dose & $33(19.5)$ & $2(2.5)$ & \\
\hline Continue treatment normally & $87(51.5)$ & $79(97.5)$ & $<0.001$ \\
\hline \multicolumn{4}{|l|}{ In fasting period } \\
\hline Not fasting & $61(36.1)$ & $30(37.0)$ & \\
\hline Skip or reduce a dose to 2 daily doses instead of 3 & $33(19.5)$ & $11(13.6)$ & \\
\hline Increase the time between 2 doses $(>12 \mathrm{~h})$ & $44(26.0)$ & $36(44.4)$ & \\
\hline Take all doses together & $31(18.3)$ & $4(4.9)$ & 0.003 \\
\hline \multicolumn{4}{|l|}{ If side effects appear } \\
\hline Stop medication & $47(27.8)$ & $4(4.9)$ & \\
\hline Continue treatment normally & $35(20.7)$ & $13(16.0)$ & \\
\hline Contact a specialist & $69(40.8)$ & $62(76.5)$ & \\
\hline $\begin{array}{ll}\text { Contact a pharmacist }\end{array}$ & $18(10.7)$ & $2(2.5)$ & $<0.001$ \\
\hline \multicolumn{4}{|l|}{$\begin{array}{l}\text { If a patient is in busy period (at work, away from home, in outdoor dinner/ } \\
\text { lunch or in travel), he forget his medication }\end{array}$} \\
\hline 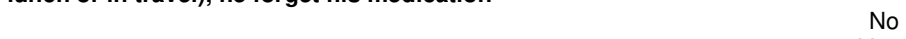 & $140(82.8)$ & $75(92.6)$ & \\
\hline Yes & $29(17.2)$ & $6(7.4)$ & 0.04 \\
\hline \multicolumn{4}{|l|}{ If no money/ health coverage, patient buys his medication } \\
\hline (25) & $65(38.5)$ & $19(23.5)$ & \\
\hline 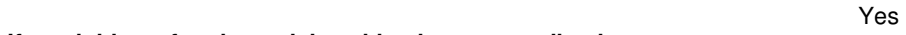 & $104(61.5)$ & $62(76.5)$ & 0.02 \\
\hline \multicolumn{4}{|l|}{ If a neighbor of patient advices him, he stop medication } \\
\hline (1) & $146(86.4)$ & $77(95.1)$ & \\
\hline Yes & $23(13.6)$ & $4(4.9)$ & 0.04 \\
\hline \multicolumn{4}{|l|}{ Frequency of neurologist clinic visits } \\
\hline Every month & $24(14.2)$ & $15(18.5)$ & \\
\hline Every $3-6$ months & $42(24.9)$ & $40(49.4)$ & \\
\hline Every year & $50(29.6)$ & $14(17.3)$ & \\
\hline Every few years (when a seizure occur) & $53(31.4)$ & $12(14.8)$ & $<0.001$ \\
\hline \multicolumn{4}{|l|}{ Experience of side effects } \\
\hline (a) & $59(34.9)$ & $48(59.3)$ & \\
\hline Yes & $110(65.1)$ & $33(40.7)$ & $<0.001$ \\
\hline \multicolumn{4}{|l|}{ Following healthcare provider instructions } \\
\hline 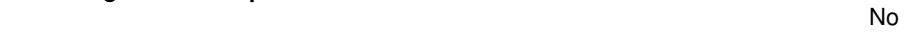 & $63(37.3)$ & $8(9.9)$ & \\
\hline Yes & $106(62.7)$ & $73(90.1)$ & $<0.001$ \\
\hline \multicolumn{4}{|l|}{ Main reason for stopping medication } \\
\hline Forgetfulness & $55(42.0)$ & 0 & \\
\hline High cost & $18(13.7)$ & $1(7.1)$ & \\
\hline Complexity of treatment regimen & $11(8.4)$ & 0 & \\
\hline Experience of side effects & $12(9.2)$ & 0 & \\
\hline Unavailability of drugs & 9 (6.9) & $10(71.4)$ & \\
\hline Perception of inefficacy & $8(6.1)$ & $2(14.3)$ & \\
\hline Absence of seizures & $18(13.7)$ & $1(7.1)$ & $<0.001$ \\
\hline Participant is satisfied and feels his treatment effective & & & \\
\hline - & $70(41.4)$ & $3(3.7)$ & \\
\hline Yes & $99(58.6)$ & $78(96.3)$ & $<0.001$ \\
\hline Participant feels his treatment is an economic burden & & & \\
\hline 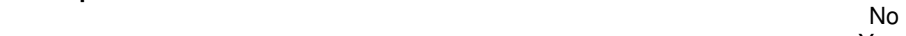 & $66(39.1)$ & $67(82.7)$ & \\
\hline Yes & $103(60.9)$ & $14(17.3)$ & $<0.001$ \\
\hline Presence of depression/ anxiety & & & \\
\hline ( & $122(72.2)$ & $68(84.0)$ & \\
\hline Yes & $47(27.8)$ & $13(16.0)$ & 0.04 \\
\hline
\end{tabular}

Non-significant variables:

Gender, Region of residence, Marital Status, Occupation, Education level, Medical insurance, Presence of comorbidities, Family history of epilepsy, Number of AE, Frequency/day, Number of drugs, Number of workers/family, Duration of disease, BMI. 
Table 4. Final results of regression using the status of attitudes as the dependent variable

\begin{tabular}{|c|c|c|c|c|}
\hline \multicolumn{2}{|c|}{ Variables } & Adjusted OR & $95 \% \mathrm{Cl}$ & $p$-value \\
\hline \multicolumn{2}{|l|}{ Age } & 0.97 & $0.94-0.99$ & 0.02 \\
\hline \multicolumn{2}{|l|}{ Presence of depression/ anxiety } & 0.4 & $0.2-0.9$ & 0.04 \\
\hline \multicolumn{2}{|c|}{ Participant is satisfied and find his treatment effective } & 4.9 & $1.2-20$ & 0.03 \\
\hline \multicolumn{2}{|c|}{ Participant feels his treatment is an economic burden } & 0.2 & $0.1-0.4$ & $<0.001$ \\
\hline \multicolumn{2}{|c|}{ Controlled epilepsy (no seizures at least 6 months) } & 3.4 & $1.6-7.1$ & 0.001 \\
\hline \multirow[t]{4}{*}{ Age onset disease } & Reference: $<12$ years & & & \\
\hline & $12-20$ years & 3.1 & $1.1-8.4$ & 0.03 \\
\hline & 20-40 years & 0.5 & $0.2-1.4$ & 0.2 \\
\hline & $>40$ years & 2.7 & $0.9-8$ & 0.08 \\
\hline \multirow[t]{4}{*}{ Frequency of neurologist clinic visits } & Reference: monthly & & & \\
\hline & Every 3-6 months & 0.7 & $0.3-2.1$ & 0.6 \\
\hline & Every year & 0.2 & $0.04-0.5$ & 0.002 \\
\hline & $\begin{array}{l}\text { Every few years (when a } \\
\text { seizure occurs) }\end{array}$ & 0.2 & $0.1-0.7$ & 0.01 \\
\hline
\end{tabular}

OR:Odds Ratio; Cl: Confidence Interval

Dependent variable: "Positive/ Negative" Attitudes.

Hosmer-Lemeshow test $p$-value $=0.7 /$ Overall predicted percentage $=79.6 \%$.

Variables excluded from the model following this order:

Family history of epilepsy, in busy period (at work, away from home, in outdoor dinner/ lunch or in travel), Following healthcare

provider instructions, Gender, Number of pills/ day, if patient forget to take medication, if no money/ health coverage, if a neighbor of participant advices him to stop medication, Experience of side effects, Occurrence seizures in the last 5 years, Attitude in fasting states. 
Table 5. Final results of regression using the seizure control as the dependent variable

\begin{tabular}{lcccc}
\hline \multicolumn{1}{c}{ Variables } & Adjusted OR & $\mathbf{9 5 \% ~ C l ~}$ & $\mathbf{p}$-value \\
\hline Attitudes status & & 1.9 & $1.1-3.4$ & $\mathbf{0 . 0 3}$ \\
Duration of disease & 1.04 & $1.02-1.07$ & $<\mathbf{0 . 0 0 1}$ \\
Do not follow neurologist's instructions in fasting period & 0.5 & $0.3-0.9$ & $\mathbf{0 . 0 3}$ \\
Attitude if seizure occurs & Reference: Double a dose & & & 0.7 \\
& Continue medication normally & 1.2 & $0.5-2.6$ & $\mathbf{0 . 0 1}$ \\
\hline
\end{tabular}

OR:Odds Ratio; Cl: Confidence Interval

Dependent variable: "Controlled epilepsy/ Uncontrolled epilepsy".

Hosmer-Lemeshow test $p$-value $=0.6 /$ Overall predicted percentage $=67.6 \%$.

Variables excluded from the model following this order:

Participant is satisfied and find his treatment effective, Following healthcare provider instructions, Gender, Number of drugs/day, Presence of tumor. 